\title{
The Social Distance of Diponegoro University Students toward Minority Ethnic Groups
}

\author{
Hapsari Dwiningtyas Sulistyani ${ }^{1}$, Turnomo Rahardjo ${ }^{2}$, Lintang Ratri Rahmiaji ${ }^{3}$ \\ \{hapsarisulistyani@yahoo.com ${ }^{1}$, turnomorahardjo@gmail.com ${ }^{2}$, lintangratri84@gmail.com ${ }^{3}$ \} \\ Universitas Diponegoro, Indonesia ${ }^{1,2,3}$
}

\begin{abstract}
The main aim of this paper is to measure the social distance between Diponegoro University (Undip) students and minority groups (ethnicity). Social distance is the degree of mindful understanding, compassionate attitude, and sympathetic behavior between two individuals or between individuals with groups that are different from themselves. Understanding the degree of social distance among people from different groups is important in a multicultural society like Indonesia. Diversity in a multicultural society has the consequence that social harmony must be built based on tolerance for differences, especially by understanding and accepting the presence of minority groups. Higher education as the last educational institution has an important role in directing the perspective of students to be more empathetic and tolerant to minority groups. This study uses a survey method involving 415 students from 31481 active students in 2019. The research measures student attitudes related to the association of individuals from a certain ethnic group (Javanese, Chinese, Sundanese, Batak, Minang, and others: Bugis, Banjar, Arabic, Malay) to Undip (any association, visiting, enroll as students). The findings show that in general most of the respondents perceive no social distance toward other student's ethnicity backgrounds. However, there is 35 percent of the respondents who perceive the social distance toward people with Papua ethnicity.
\end{abstract}

Keywords: Social Distance, Minority Ethnic Groups, University Students.

\section{Introduction}

Theoretically, social distance can be understood as the degree of thoughtful understanding, positive attitude, and sympathetic behavior between two individuals or toward individuals or groups that are different from themselves [1]. Social distance will be larger if an individual denies interacting with people from different cultural backgrounds or in this paper case with people from different ethnicities. Sympathetic understanding, attitude, and behavior towards people from different groups are important in a multicultural society like Indonesia. Diversity within a culturally plural society has the consequence that social harmony needs to be built based on tolerance for differences, especially by understanding and accepting the presence of minority groups.

According to the National Commission of Human Rights [2], the scope of minority groups in the Indonesian context is very diverse, which at least includes minority groups based on ethnicity, race, religion/belief, disability, and sexual orientation/gender identity. This diversity shows that one of the important requirements to build social harmony in Indonesia is awareness in understanding and fostering good relations with various minority groups. 
The potency of intolerance behaviors toward different groups, especially minority groups, is increasing. The intolerance was apparent in the results of a Wahid Foundation study in collaboration with the Indonesian Survey Institute (LSI) in 2016 [3]. The study, entitled the potential religious intolerance and radicalism among Indonesian Muslims, was conducted in 34 provinces in Indonesia and involving 1520 respondents. The results of the Wahid Foundation research show the strengthening of intolerance behaviors in Indonesia. The research signified that 59.9 percent of respondents have a group that they hate. The hated groups include those who are non-Muslim, communist, Chinese and others.

Hatred towards minority groups will be stronger if educational institutions do not provide an adequate understanding of the importance of tolerance to diversity. The educational institutions are a very prominent apparatus in providing a basic understanding of the existence of the minority groups. Furthermore, the educational institution is important in raising the mindful attitude of the young generation to the minority groups. But ironically, the Wahid Foundation research indicated that the teaching staff in the educational institutions have a relatively high level of intolerance. A survey conducted by PPIM UIN Syarif Hidayatullah Jakarta in 2018 of 2237 that researching Muslim teachers at the level of kindergarten to high school showed the level of intolerance and radicalism of the teachers [4]. The study found that 21 percent of respondents banned other religious events in their neighborhoods. While related to radical understanding, there are 41.26 percent of the 2237 respondents were in a radical position. Furthermore, as many as 56 percent of the teaching staff disagree with the establishment of non-Muslim schools. These findings indicate that educators from the elementary to secondary education level tend to have intolerance towards different religious groups, and even have a radical understanding.

The intolerance point of view of educators from the elementary to secondary level certainly plays a significant role in shaping students' understanding, attitudes, and behavior towards minority groups. University as the last educational institution has a very important role in direct and foster the perspective of students to be more empathetic and tolerant towards minority groups. Moreover, students from a tertiary institution are the melting point of various diversity groups in Indonesia. The strategy in shaping the attitudes and the behaviors of tolerance must, certainly, be based on an understanding of the social distance that exists between students and minority groups.

\section{Research Method}

There are three approaches in the research of intercultural communication, namely Social Science, Interpretive, and Critical approaches. Each approach has different assumptions of ontology, epistemology, axiology, and methodology. Research on Social Distance of Diponegoro University Students uses the Social Science approach. This approach has the following assumptions; the external reality that can be explained, human behavior can be predicted, the researcher's goal is to explain and predict behavior, culture is a variable that can be measured, and culture will affect communication. Thus, the Social Science paradigm is used as a basis for explaining and predicting the behavior of Diponegoro University students related to social distance from ethnic minorities.

This study examines the social distance (tolerance level) of Diponegoro University students against ethnic minority groups by involving 415 students from 31481 active students in 2019. The research uses a non-probability sample technique with consideration to the 
proportion of student numbers in each faculty. The sample comes from 11 faculties in Undip (Faculty of Medicine, Engineering, Science and Mathematics, Animal Husbandry and Agriculture, Fisheries and Maritime Affairs, Public Health, Psychology, Law, Economics and Business, Cultural Sciences, and Social and Political Sciences) and Schools of Vocational. The number of respondents in each faculty is around 34-37 people or each faculty is represented by $8.2 \%-8.9 \%$ of all the respondents. The measured social distance is related to the respondents' opinions on what if an individual from different ethnicity (Javanese, Chinese, Sundanese, Batak, Minang, and other ethnicities such as Bugis, Banjar, Arabic, and Malay) has affiliations with Undip (visiting, utilizing campus facilities, enrolling as a student), based on how she or he perceives her or his ethnic identity.

\section{Results and Discussion}

The respondents in this study are 415 Undip students. Most of them (68.2\%) are female and the remaining $31.2 \%$ are male students. Most of the students (89.6\%) are Muslim. While other respondents are Christians (5.1\%), Catholics (4.6\%), Buddhists (0.5\%), and Confucians $(0.2 \%)$. They come from diverse cultural (ethnic) backgrounds. Majority of them are Javanese (70.6\%), while the rest are Minang (3.9\%), Batak (3.9\%), Sundanese (5.5\%), Chinese (1.7\%), and other categories: Bugis, Banjar, Malay, Arabic, and others (14.5\%).

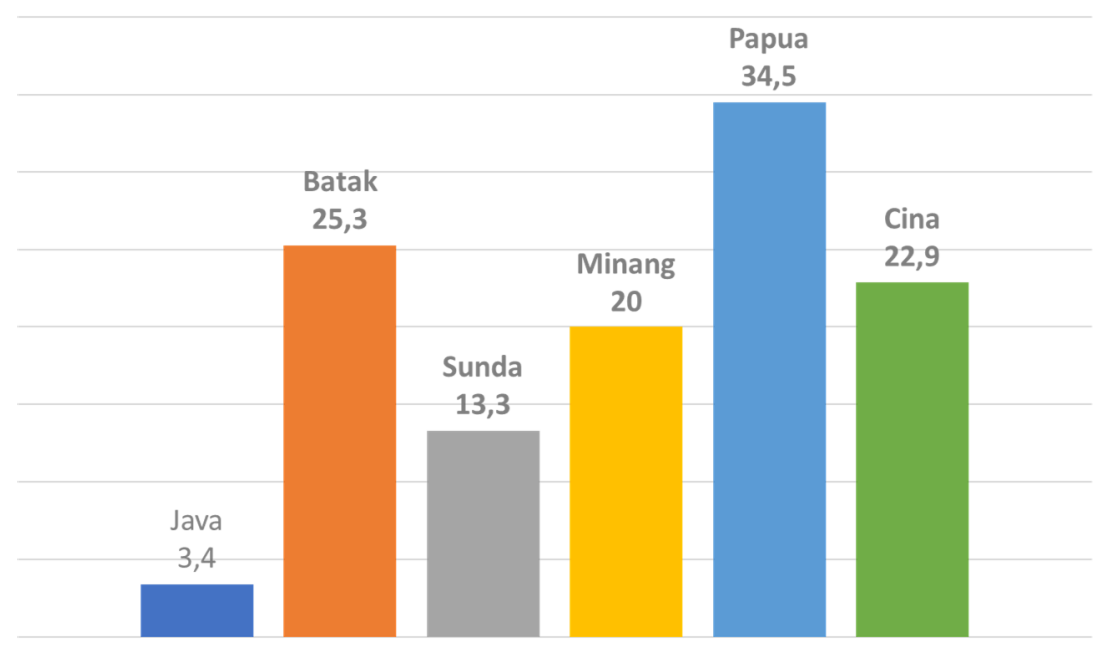

Fig. 1. Social Distance by Ethnicity (\%).

Based on the ethnic background, it can be said that the percentage of respondents' social distance toward various ethnicities is varied. The lowest percentage is the social distance toward the Javanese people. Only 3,4 percent of respondents perceived the social distance to Javanese people. The percentages of respondents who perceived a social distance to Chinese, Sundanese, Batak, and Minang ethnicities are also relatively low (the range is from $15 \%$ to $25 \%$ ). However, the number of respondents who perceive a social distance toward Papuan is relatively higher than that of other ethnicities. The result shows that 34,5 percent of the respondent has a social distance toward Papuan. The findings show that the percentage of 
social distance toward various ethnic groups is relatively low but the percentage of that on Papuan is sightly higher than on the other ethnicities. In the context of associations with Undip in general (visiting campus, utilizing facilities in terms of tourism, sports, and praying in Undip Mosque), most students (more than 90\%) do not question the presence of individuals from any ethnicity to use the existing facilities on the Undip campus. Only a small proportion of the respondent (less than 5\%) "deny" the presence of people from particular ethnic backgrounds to have any association with Undip. For example, few students are rejecting individuals from Chinese, Sundanese, Batak, Minang, and Papuan to use existing facilities on campus. In the context of their views and attitudes toward individuals from various ethnicities for enrolling as Undip students, almost all (more than 95\%) the respondents state their agreement. They can accept the presence of individuals from other ethnicities to enroll as Undip students. All students who were participating as respondents in this study did not have any objection to Javanese, Sundanese, Minang, and Papuan people to become Diponegoro University students. Only a small number of respondents deny people with Chinese and Batak ethnicities for officially enrolling as Diponegoro University students.

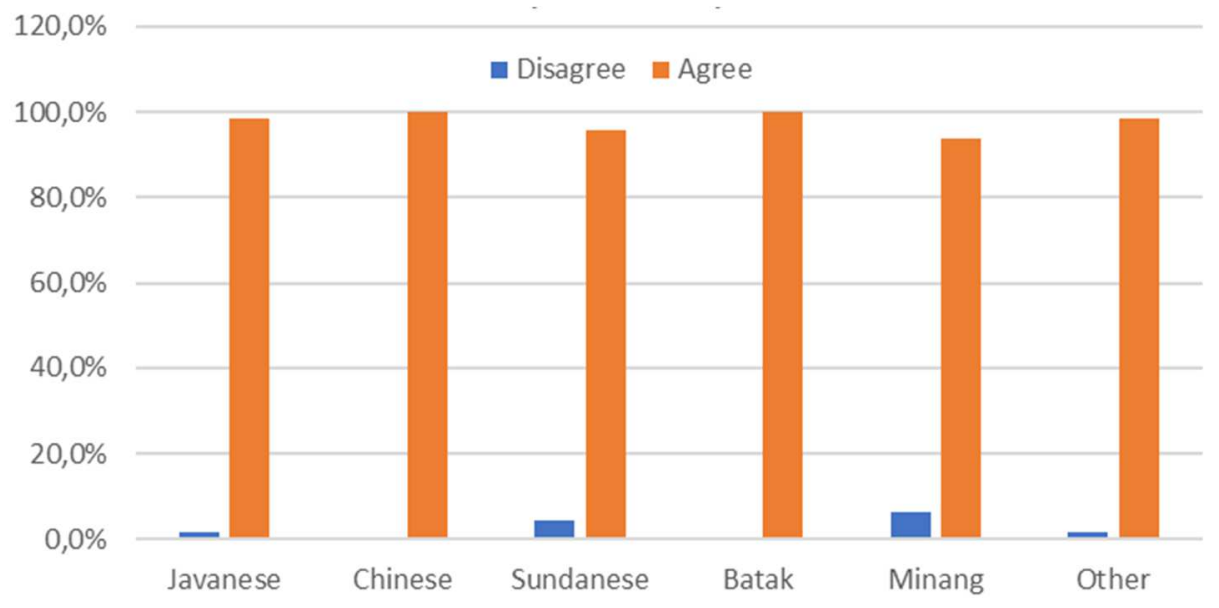

Fig. 2. Perception of Chines Using the Campus Facilities by Ethnicity.

Identity is an abstract concept and has many facets that play a significant role in intercultural interaction [5], Identity is significant for most people because identity talks about who we are, who other people are, how we understand who we are, and how we communicate our identity to others. Identity functions as a bridge between culture and communication. Identity is important because we communicate our identity to others and we learn to know who we are through communication [6].

Cultural identity is a feeling of belonging to or affiliating with particular cultural groups. Cultural identity can also be seen as membership in a group where all people share the same symbolic meaning. Cultural identity can be divided into three levels, namely personal, relational, and communal identity [5]. Cultural identity talks about similarities and differences. Cultural identity can also lead to the emergence of stereotypes, prejudice, racism, and ethnocentrism. Differences in identity can cause social conflict.

At the conceptual level, a stereotype is a term used to refer to negative or positive assessments of individuals based on certain group memberships, strongly held beliefs about 
groups of people, or negative images attached to outgroups [7][6][8]. Prejudice refers to an irrational negative perception or hatred of a particular group that usually based on race, religion, or sexual orientation differences. Stereotypes and prejudices are interrelated because both assess individuals based on their specific group membership [7]. Another definition states that prejudice is an attitude (usually negative) towards a cultural group that is based on little or no experience or evidence at all. Prejudice is a deep negative feeling. This sentiment is in the form of anger, fear, hatred, and anxiety [6][5]. Ethnocentrism refers to the level or tendency in which a person sees his culture superior to other people's culture or negatively evaluates the culture of others by using our cultural standards [9][7][5].

Various social constraints such as stereotypes, prejudice, and discrimination are closely related to social distance. In general, social distance is perceived as a social concept that cannot be interpreted simply as a distance or biological/genetic distance. The study on technological links has shown that humans can feel the social distance and social closeness without having to be physically in the same room/place [10]. The concept of social distance that specifically looks at the closeness of affection is the social distance proposed by Bogardus. The concept of social distance is based on the notion that those who are socially close to us are those we consider alike to us. According to Bogardus [10], feelings of sympathy and affection are essential factors of social distance. When there are lacking understanding and sympathy, social distance arises. Whereas if understanding and sympathy are high then social distance will be close [10]. He argued the focus of attention in the study of social distance was the reaction of someone's feelings towards other people or groups of people.

Intercultural interaction is a symbolic exchange process whereby two or more individuals from different cultural communities negotiate meaning exchanged in an interactive framework. Everyone from different cultural backgrounds establishes direct or indirect contact. Different culture, among others, is within the scope of nationality, ethnicity, and religion. In today's global situation, the important thing to do is how we can communicate effectively with people who are culturally different. In a sense, how anyone can reduce the occurrence of cultural misunderstanding or cultural misunderstanding, not the creation of closeness or relational satisfaction [8]. Cultural misunderstandings have the potential to create tension and conflict, on the other hand, recognition of cultural differences will enable everyone to establish more meaningful relationships. Thus, the challenge faced is how everyone is willing to "learn" to accept cultural differences.

The findings of this study show that there is only a small number of respondents who perceive a social distance to people who have various ethnic backgrounds. Many of Diponegoro University students can accept the existence of individuals or friends in studying in tertiary institutions of different ethnic origins. This condition shows that intercultural interaction or communication between them can work well, with no indication of overt ethnocentrism, negative stereotypes, prejudices, and discrimination to people of different ethnicities.

Referring to the Theory of Negotiation of Identity, Stella Ting-Toomey is interested in how identity influences interactions [11]. She began her theoretical explanation by distinguishing between personal identity and cultural identity. Cultural identity (such as race, ethnicity, religion, and gender) is associated with membership in a particular culture or social group; whereas personal identity has more unique characteristics, including interests, abilities, and preferences that distinguish one person from another. Cultural and ethnic identity is characterized by two dimensions, namely value content and salience. Value content contains 
types of evaluations based on cultural beliefs. Salience, on the other hand, is the power of affiliation felt in particular groups in particular situations.

Ting-Toomey is particularly interested in how individuals manage or negotiate the pressure between the personal and cultural self in ways that can increase respect for other cultural groups. Some individuals are more effective than others in getting a balance between personal identity and cultural identity, for example, when an individual knows that he or she has to balance between maintaining a strong sense of self and considering/understanding the identities of others as well as respecting their identities. Ting-Toomey called this situation as functional biculturalism. Furthermore, Ting-Toomey also explains the state when an individual can move from one cultural context to another cultural situation mindfully and easily, it indicates that that individual has reached a state that can be called as a cultural transformer. The key to becoming a cultural transformer to comprehend intercultural competence skills.

\section{Conclusion}

This study aims to measure the social distance of Undip students to particular ethnic groups. The conclusion that can be conveyed in this study is that in general in the context of associations/links with Undip it can be said that most students from diverse ethnic backgrounds do not question the presence of individuals of any ethnicity to use the facilities available at the Undip campus. In addition, in the context of their views and attitudes about individuals from various ethnicities to enroll as Undip students, almost all of them express their agreement. That is, they can accept the presence of individuals from other ethnicities to become Undip students.

However, compared to other ethnicities the number of respondents who perceive a social distance toward Papuan, Bataknese, and Chinese is relatively high. The result shows that 34,5 percent of the respondent perceives a social distance toward Papuan, whereas the percentage of social distance toward Bataknese and Chinese are 26,5 percent and 22,9 percent respectively. In other words, even though the research findings show that the percentage of social distance toward various ethnic groups is relatively low but there are some ethnicities that the respondents perceived as further than the others in terms of social distances. Therefore, the university should be conducting cultural diversity awareness programs in order to reduce, ethnicity related, social distance gaps. The program is important because the main aim of the program is to teach the student how to communicate in a culturally sensitive situation. The student will master all the skills needed for becoming a cultural competence communicator.

As cultural competence communicators, the students will be able to communicate with people from different ethnic groups mindfully so that communication between individuals of different ethnicities can be done effectively. They do not express ethnocentric attitudes/behavior, stereotypes, prejudices, and discrimination toward people that have different ethnic backgrounds. The mindful cultural communication process can also be referred to two particular conceptual thinking known as functional biculturalism, which is the balance in maintaining a strong sense of self while respecting the identity (ethnic) of others and cultural transformers, which can move from one cultural context to another in a mindful and easy manner. 


\section{References}

[1] N. Javakhishvili, J. F. Schneider, A. Makashvili, and N. Kochlashvili, "Measuring ethnic attitudes: Tolerance and social distance from cross-cultural perspective," in Atiner Conference Paper Series, No: PSY2013-0543, 2013.

[2] K. HAM, "Upaya Negara Menjamin Hak-Hak Kelompok Minoritas di Indonesia: Sebuah Laporan Awal (State Efforts in Protecting Minority Rights in Indonesia: An Initial Report)," Jakarta Komnas HAM, 2016.

[3] W. Institute, "Ringkasan Eksekutif Laporan Tahunan: Kemerdekaan Beragama dan Berkeyakinan Tahun 2016 Wahid Foundation." .

[4] P. U. S. Hidayatullah, "Gempa Toleransi Mengancap Indonesia." [Online]. Available: https://edukasi.kompas.com/read/2018/11/30/19280211/gempa-intoleransi-mengancamindonesia. (2018).

[5] L. Samovar and R. Porter, "MacDaniel Communication between cultures Canada," Wadsworth.-2009.-496 p, 2009.

[6] J. N. Martin and T. K. Nakayama, Intercultural communication in contexts. McGraw-Hill New York, NY, 2013.

[7] F. E. Jandt, An introduction to intercultural communication: Identities in a global community. Sage Publications, 2017.

[8] J. Barlow and C. Møller, A complaint is a gift: Using customer feedback as a strategic tool. Berrett-koehler publishers, 1996.

[9] J. W. . Neuliep, Intercultural Communication, A Contextual Approach. California: Sage Publications, 2006.

[10] N. Karakayali, "Social distance and affective orientations 1," in Sociological Forum, 2009, vol. 24, no. 3, pp. 538-562.

[11] S. W. K. A. F. \& J. G. Littlejohn, Oetzel: Theories of Human Communication. Illinois: Waveland Press, 2017. 